\title{
Should ancillary brain blood flow analyses play a larger role in the neurological determination of death?
}

\section{Les analyses secondaires du débit sanguin cérébral devraient-elles jouer un rôle plus important dans le diagnostic de décès neurologique?}

\author{
Derek J. Roberts, MD • Kate A. M. MacCulloch, MD • \\ Eric J. Versnick, MD $\cdot$ Richard I. Hall, MD
}

Received: 16 February 2010/Accepted: 6 July 2010/Published online: 13 August 2010

(c) Canadian Anesthesiologists' Society 2010

\begin{abstract}
Purpose We present two patients who regained spontaneous respiration following clinical neurological determination of death (NDD) while ancillary radiological imaging demonstrated brain blood flow.

Clinical features A 26-yr-old male with chronic otitis media presented with a Glasgow Coma Scale (GCS) score of 3 and fixed 7-mm pupils. Computed tomography demonstrated right-sided mastoiditis and a temporal lobe abscess associated with uncal herniation. The patient was diagnosed brain dead seven-hr later when motor responses and brainstem reflexes were absent and his apnea test was positive. Approximately 28-hr after NDD, during
\end{abstract}

This article is accompanied by an editorial. Please see Can J Anesth 2010; 57(10).

\section{J. Roberts, MD}

Department of Surgery, University of Calgary and the Foothills Medical Centre, Calgary, AB, Canada

D. J. Roberts, MD - K. A. M. MacCulloch, MD - R. I. Hall, MD Division of Critical Care Medicine, Department of Medicine, Dalhousie University and the Queen Elizabeth II Health Sciences Centre, Halifax, NS, Canada

\section{E. J. Versnick, MD}

Division of Neuroradiology, Department of Radiology, Dalhousie University and the Queen Elizabeth II Health Sciences Centre, Halifax, NS, Canada

\section{R. I. Hall, MD ( $\square)$}

Departments of Anesthesia, Pharmacology, and Surgery,

Dalhousie University and the Queen Elizabeth II Health

Sciences Centre, Halifax, NS, B3H 3A7, Canada

e-mail: rihall@dal.ca post-declaration organ resuscitation, the patient regained spontaneous respiration and magnetic resonance imaging revealed brain blood flow. Spontaneous respirations persisted for five-days before cardiovascular collapse occurred. In the second case, a 50-yr-old female presented with a GCS score of 3 and fixed 6-mm pupils following a traumatic brain injury and a five-minute cardiac arrest. The patient was deemed clinically brain dead six-hr later when physical examination revealed absent motor responses and brainstem reflexes and her apnea test was positive. As confirmation of brain death, a cerebral radionuclide angiogram was performed, which surprisingly revealed intracranial arterial flow. During organ resuscitation, 11-hr after NDD, the patient regained spontaneous respiration. She expired hours after family decision to withdraw treatment.

Conclusion For both patients, several unrecognized confounding factors for NDD were present. These cases illustrate the difficulties encountered by experienced clinicians in determining brain death using clinical criteria alone, and they suggest that more routine use of ancillary brain blood flow analyses should be recommended.

Résumé

Objectif Nous présentons les cas de deux patients qui ont recommencé à respirer spontanément après avoir reçu un diagnostic de décès neurologique clinique alors que l'imagerie radiologique secondaire démontrait un debit sanguin cérébral.

Éléments cliniques Un homme de 26 ans souffrant d'otite moyenne chronique s'est présenté avec un score de 3 sur l'échelle de coma de Glasgow (GCS) et des pupilles fixes à $7 \mathrm{~mm}$. La tomodensitométrie a montré une 
antro-mastoïdite droite et un abcès au lobe temporal associé à une herniation uncinée. La mort cérébrale a été diagnostiquée chez le patient sept heures plus tard, lorsque les réponses motrices et les réflexes du tronc cérébral ont cessé et que le test d'apnée était positif. Environ $28 \mathrm{~h}$ après le diagnostic $d u$ décès neurologique, pendant la réanimation pour préserver les organes, le patient a recommencé à respirer spontanément et l'imagerie par résonance magnétique a révélé un débit sanguin cérébral. Les respirations spontanées ont continué durant cinq jours avant la survenue d'un collapsus cardiovasculaire. Dans le deuxième cas, une femme de 50 ans s'est présentée avec un score de 3 sur l'échelle GCS et des pupilles fixes à $6 \mathrm{~mm}$ à la suite d'une lésion cérébrale traumatique et d'un arrêt cardiaque de cinq minutes. La mort cérébrale a été diagnostiquée chez la patiente six heures plus tard lorsque l'examen physique a révélé qu'il n'y avait plus de réponse motrice ni de réflexe du tronc cérébral et que le test d'apnée était positif. Pour confirmer la mort cérébrale, une angiographie isotopique cérébrale a été réalisée, laquelle a curieusement révếé un débit artériel intracrânien. Pendant la réanimation des organes $11 \mathrm{~h}$ après le diagnostic $d u$ décès neurologique, la patiente a recommencé à respirer spontanément. Elle est décédée quelques heures après la décision de la famille de ne pas la traiter.

Conclusion Chez les deux patients, plusieurs variables parasites non reconnues pour le diagnostic du décès neurologique étaient présentes. Ces cas illustrent les difficultés rencontrées par des cliniciens d'expérience lorsqu'ils doivent déterminer la mort cérébrale sur la base de critères cliniques seulement, et suggèrent qu'une utilisation plus fréquente d'analyses secondaires du débit sanguin cérébral pourrait être de mise.

Guidelines for neurological determination of death (NDD) in adults vary both nationally and internationally. ${ }^{1-4}$ Most guidelines emphasize that brain death is a clinical diagnosis requiring exclusion of confounding factors, presence of an irreversible coma without motor responses, lack of all brainstem reflexes, and apnea. ${ }^{1,5,6}$ Apnea should be confirmed with an apnea test, which verifies a lack of spontaneous respiration during induced acute hypercarbia. ${ }^{1,5,7}$

Although clinical examination and judgement are primarily recommended for NDD, they are frequently confounded by metabolic disturbances, ocular injuries or pupillary paralysis, heavy sedation, and trauma to the middle or inner ears, among others. ${ }^{8}$ Even the apnea test uncommonly yields false-positive results, such as when patients have diseases that result in carbon dioxide retention. ${ }^{7}$ Furthermore, apnea testing is precluded in $7 \%$ of patients due to cardiorespiratory instability, necessitating use of confirmatory tests. ${ }^{9}$

Radiological studies that demonstrate absent brain blood flow are utilized for confirmation of neurological death when clinical examination and/or apnea testing is inconclusive or when confounding factors are present. ${ }^{8}$ However, such ancillary studies are not universally recommended for NDD in present Canadian guidelines. ${ }^{5,8}$ Herein, we report two patients who regained spontaneous respiration following clinical NDD while ancillary radiological imaging demonstrated the presence of brain blood flow. As there were several unrecognized confounding factors, these cases illustrate the difficulties encountered by experienced clinicians in determining brain death using clinical criteria alone, and suggest that more routine use of ancillary brain blood flow analyses should be recommended.

\section{Case reports}

The authorized legal next of kin provided written informed consent to allow publication of each respective case report.

\section{Case 1}

History, clinical examination, initial neuroimaging, and results of the apnea test

A 26-yr-old male with a three-month history of otitis media was taken to a regional Emergency Department (ED) after becoming rapidly unresponsive. On arrival, his temperature was $40.3^{\circ} \mathrm{C}$, his blood pressure and heart rate were normal, and he had a Glasgow Coma Scale (GCS) score of 3 and fixed 7-mm pupils. The airway was secured with an endotracheal tube while rocuronium, acetaminophen, dexamethasone, and mannitol were given. A computed tomography (CT) scan of the patient's head revealed a right temporal lobe abscess associated with perilesional edema, leftward midline shift, uncal herniation, and mastoiditis (Fig. 1). Clindamycin and vancomycin were administered, and the patient was airlifted to the Queen Elizabeth II Health Sciences Centre (QEII HSC), the major tertiary neurosurgical centre for the Atlantic Provinces.

Seven-hr after coma onset, the patient was independently assessed for the presence of brain death by an intensivist and a neurosurgeon according to Canadian Forum recommendations. ${ }^{5}$ No sedative agents had been administered and a train-of-four test indicated normal neuromuscular function. The patient had a GCS score of 3 and fixed 7-mm pupils. He lacked respiratory efforts, corneal reflexes, and motor responses to pain. Otoscopy was normal without evidence of middle ear effusion. 

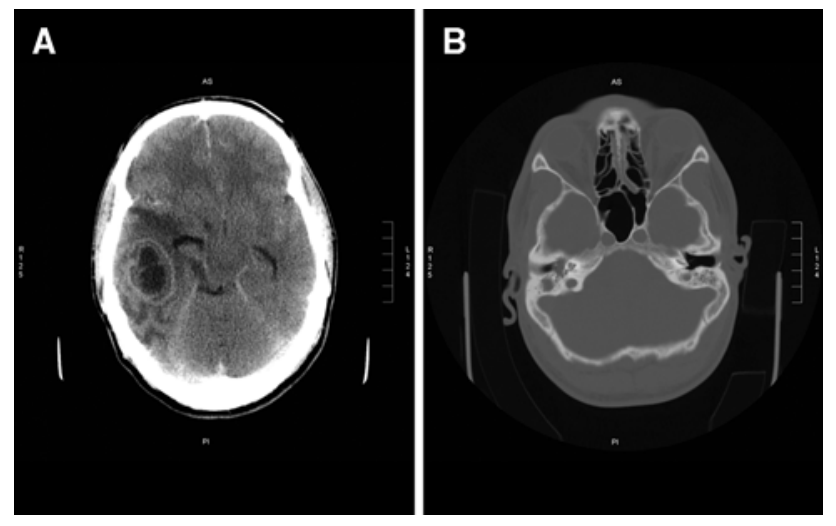

Fig. 1 Presenting contrast-enhanced (A) and bone window (B) axial computed tomography images for Case 1. A) There is a $3.3-\mathrm{cm}$ irregular and minimally-enhancing encapsulated lesion in the right temporal lobe associated with surrounding vasogenic edema, local mass effect, uncal herniation, and leftward midline shift of approximately $1.3-\mathrm{cm}$. B) Note also the presence of mastoid air cell destruction representing mastoiditis

Vestibulo-ocular reflexes were absent bilaterally, as were oculocephalic, gag, and cough reflexes. The patient's temperature was $36.5^{\circ} \mathrm{C}$, and there was no evidence of shock or drug intoxication (serum levels of amphetamines, barbiturates, benzodiazepines, cannabinoids, cocaine, ethanol, and opioids were undetectable, and there were no tricyclic antidepressants present in urine).

An arterial blood gas (ABG) sample was drawn and revealed the following: $\mathrm{pH} 7.35, \mathrm{PaCO}_{2} 42 \mathrm{mmHg}, \mathrm{PaO}_{2}$ $234 \mathrm{mmHg}$, and $\mathrm{HCO}_{3}^{-} 23 \mathrm{mmoL} \cdot \mathrm{L}^{-1}$. The patient was pre-oxygenated for five-min with a $\mathrm{F}_{1} \mathrm{O}_{2}$ of 1.0 and was subsequently removed from the ventilator. He was placed on $4 \mathrm{~L}$ of oxygen per minute via a cannula placed in the endotracheal tube, and $\mathrm{ABG}$ samples were then obtained every two-min. At two-min, the $\mathrm{ABG}$ results were: $\mathrm{pH}$ 7.26, $\mathrm{PaO}_{2} 468 \mathrm{mmHg}$, and $\mathrm{PaCO}_{2} 56 \mathrm{mmHg}$; at four-min, they were: $\mathrm{pH} 7.21, \mathrm{PaO}_{2} 457 \mathrm{mmHg}$, and $\mathrm{PaCO}_{2}$ $63 \mathrm{mmHg}$; and at six-min, they were: $\mathrm{pH} 7.18, \mathrm{PaO}_{2}$ $393 \mathrm{mmHg}$, and $\mathrm{PaCO}_{2} 69 \mathrm{mmHg}$. For a total of 10-min, an intensivist and a neurosurgeon continuously observed the patient to be apneic. He was subsequently diagnosed brain dead.

\section{Intensive care unit management post-NDD}

The family agreed to organ donation. Due to Escherichia coli growth in blood cultures, the plan was to reassess eligibility for donation after 48-hr. Patient management post-declaration included mechanical ventilation, intravenous fluids, use of a Bair Hugger ${ }^{\circledR}$ as needed to maintain body temperature within normal range, dopamine and vasopressin infusions to maintain mean arterial pressure from 65 to $70 \mathrm{mmHg}$, and administration of clindamycin, ceftriaxone, metronidazole, methylprednisolone, Humulin
$\mathrm{R}$ (as required to maintain a plasma glucose of 4.4 to 6.1 $\mathrm{mmoL} \cdot \mathrm{L}^{-1}$ ), and potassium chloride (as needed based on plasma electrolyte values).

To further delineate the anatomy of the temporal lobe abscess and to exclude involvement of extracranial vascular structures (which could have precluded consideration for donation), magnetic resonance imaging (MRI) of the patient's brain was performed two-hr after declaration. The MRI revealed the temporal lobe abscess with associated uncal and tonsillar herniation, descent and deformation of the brainstem, effacement of the basal cisterns, and generalized cerebral edema (Fig. 2A-B). Surprisingly, however, brain blood flow was present (Fig. 2B-D).
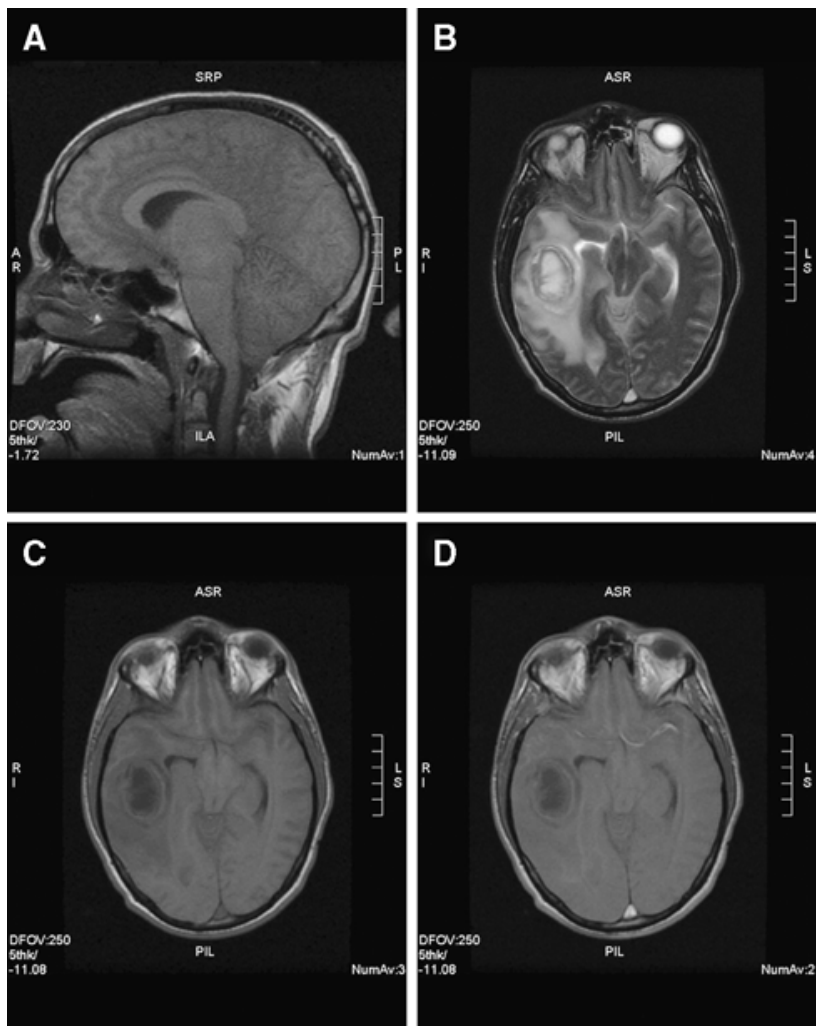

Fig. 2 Magnetic resonance images obtained two-hr following the apnea test and neurological determination of death for Case 1. A) Sagittal T1-weighted image demonstrating generalized cerebral edema with loss of grey-white matter differentiation, effacement of the anterior basal cisterns, and tonsillar herniation. B) Axial T2weighted image revealing a right-sided temporal lobe abscess with hypointense abscess capsule and surrounding hyperintense vasogenic edema. Local mass effect with distortion and shift of the brainstem is also identified along with uncal herniation. Hypointensity in the middle cerebral artery (MCA) flow void indicates the presence of arterial flow in the MCA, whereas the hyperintense signal in the sigmoid sinus flow void represents absent or near-absent sigmoid sinus flow. C) Axial T1-weighted pregadolinium image is shown for comparison with the postgadolinium image. D) Axial T1-weighted postgadolinium image demonstrates enhancement of the MCA, particularly on the left, indicative of intracranial arterial flow (albeit slow arterial flow given the lack of abscess capsule enhancement) 
Fig. 3 Magnetic resonance (MR) and MR venography (MRV) images obtained following the return of spontaneous respiration for Case 1. A) Sagittal T1-weighted MR image demonstrating worsening of the previously identified generalized cerebral edema with further tonsillar herniation, distortion of the brainstem, and obliteration of the anterior basal cisterns. B) Sagittal raw data image of a phase contrast MRV revealing absent venous outflow. C) Anterior view of a threedimensional MRV showing absent intracranial venous outflow; the flow seen is entirely extracranial (of note, although there is a lack of intracranial venous outflow, we have no T2-weighted or postgadolinium images to prove that brain arterial flow was also absent)

\section{Return of spontaneous respiration and subsequent neuroimaging}

Approximately 28-hr after coma onset, the patient began triggering the ventilator and was found to have a spontaneous respiratory rate of $>10$ breaths $\cdot \mathrm{min}^{-1}$ (ABG result 20 min prior: $\mathrm{pH}$ 7.40, $\mathrm{PaO}_{2} 100 \mathrm{mmHg}, \mathrm{PaCO}_{2} 35 \mathrm{mmHg}$ on a $\mathrm{F}_{\mathrm{I}} \mathrm{O}_{2}$ of 0.3 ). The mode of ventilation was switched from assist control to pressure support. His neurological status was reassessed by a second neurosurgeon, and no change from his previous NDD examination was found aside from spontaneous respirations.

The patient was removed from the organ donor list. A repeat MRI demonstrated worsening of cerebral edema, further tonsillar herniation, and the complete absence of intracranial venous outflow (Fig. 3A-C). After five-days, the spontaneous respirations decreased and the patient underwent cardiovascular collapse and expired.

\section{Neuropathological findings}

An autopsy was performed. The right temporal bone revealed changes consistent with chronic otitis media with secondary chronic osteomyelitis. There were no acute inflammatory changes in the middle ear or middle ear effusion. There was a necrotic cavity in the right temporal lobe from which colonies of gram-positive diplococci were cultured. Sections of right temporal lobe revealed recent infarction, while more selective neuronal necrosis was seen in remaining cortical regions. There were also ischemic changes in the pons and medulla.

\section{Case 2}

History, clinical examination, initial neuroimaging, and results of the apnea test

A 50-yr-old female was found unresponsive following a fall down one flight of stairs. Upon arrival of Emergency Medical Services personnel, her GCS score was 3 and she had fixed 6-mm pupils. Her electrocardiogram showed pulseless electrical activity, and after five-min of advanced cardiac life
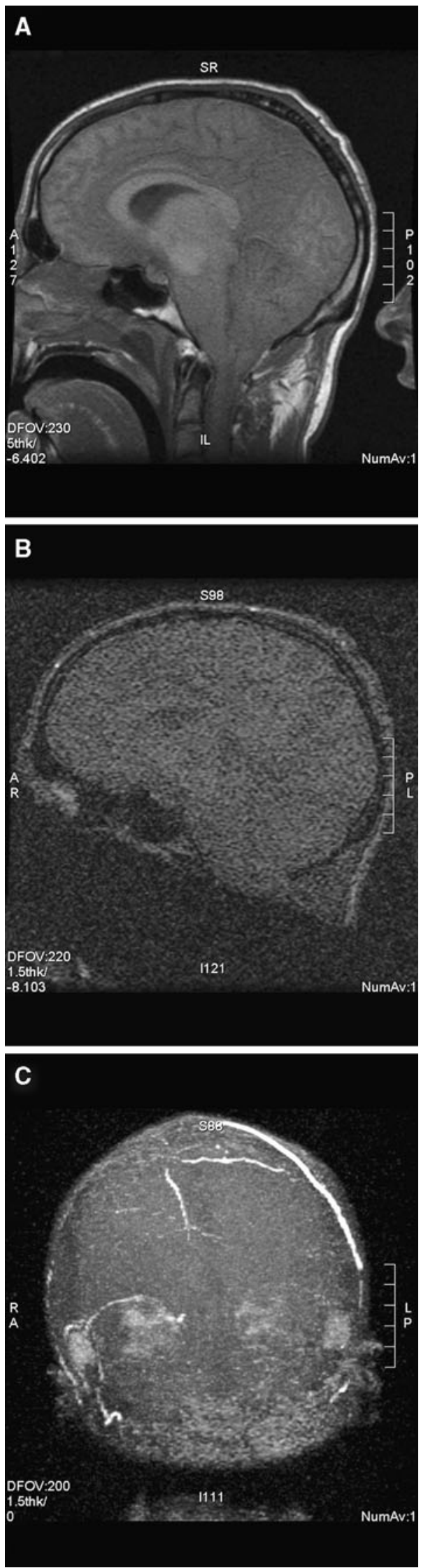
Fig. 4 Presenting axial computed tomography images for Case 2. A) Unenhanced image demonstrating right-sided extracranial soft tissue swelling, loss of grey-white matter differentiation with sulcal effacement indicative of generalized cerebral edema, layering of subdural blood along the tentorium cerebelli, and effacement of the anterior basal cisterns. B) Unenhanced image showing sulcal effacement, loss of grey-white matter differentiation (left side worse than right), traumatic subarachnoid hemorrhage, and a left frontal acute subdural hematoma. C) Image filmed in bone windows revealing a right occipital bone fracture and a left-sided foramen magnum fracture

support, there was return of sinus rhythm. After arrival at a regional hospital, endotracheal intubation was performed and the patient was transferred to the QEII HSC. A head CT demonstrated a basal skull fracture, a subdural hematoma, traumatic subarachnoid hemorrhage, generalized cerebral edema, and effacement of the basal cisterns (Fig. 4A-C).

Six-hr following onset of coma, two intensivists independently assessed the patient for the presence of brain death, as above..$^{5}$ The patient had a GCS score of 3 and fixed 6-mm pupils. She lacked corneal reflexes, spontaneous respirations, and motor responses to pain. Otoscopy did not reveal otorrhea or hemotympanum. Vestibulo-ocular reflexes were absent bilaterally, as were oculocephalic, gag, and cough reflexes. The temperature of the patient was $36.5^{\circ} \mathrm{C}$ and her blood pressure and heart rate were normal. No sedative or neuromuscular blocking agents had been administered. Toxicology screening was negative, basic laboratory testing did not reveal any abnormality, and blood cultures were negative.

An ABG sample was drawn and revealed the following: pH 7.28 and $\mathrm{PaCO}_{2} 56 \mathrm{mmHg}$. The patient was pre-oxygenated, and then an oxygen cannula was placed in the endotracheal tube following disconnection from the ventilator, as was described above. The subsequent $\mathrm{ABG}$ results at three-min were: $\mathrm{pH} 7.20$ and $\mathrm{PaCO}_{2} 68 \mathrm{mmHg}$, and the results at six-min were: $\mathrm{pH} 7.15$ and $\mathrm{PaCO}_{2} 80 \mathrm{mmHg}$. The patient was continuously observed to be apneic for a total of eight-min. She was subsequently deemed clinically brain dead.

Intensive care unit management post-NDD, subsequent neuroimaging, and return of spontaneous respiration

Organ resuscitation, as described above (see Case 1), was initiated. $^{10}$ Given our experience with the first case (including family request after discussion) and in accordance with Canadian Forum guidelines, ${ }^{5}$ a cerebral radionuclide angiogram was performed as radiological confirmation of brain death and, surprisingly, intracranial arterial flow was visualized (Fig. 5).

Eleven-hr after coma onset, the patient began triggering the ventilator and spontaneous respirations were noted with
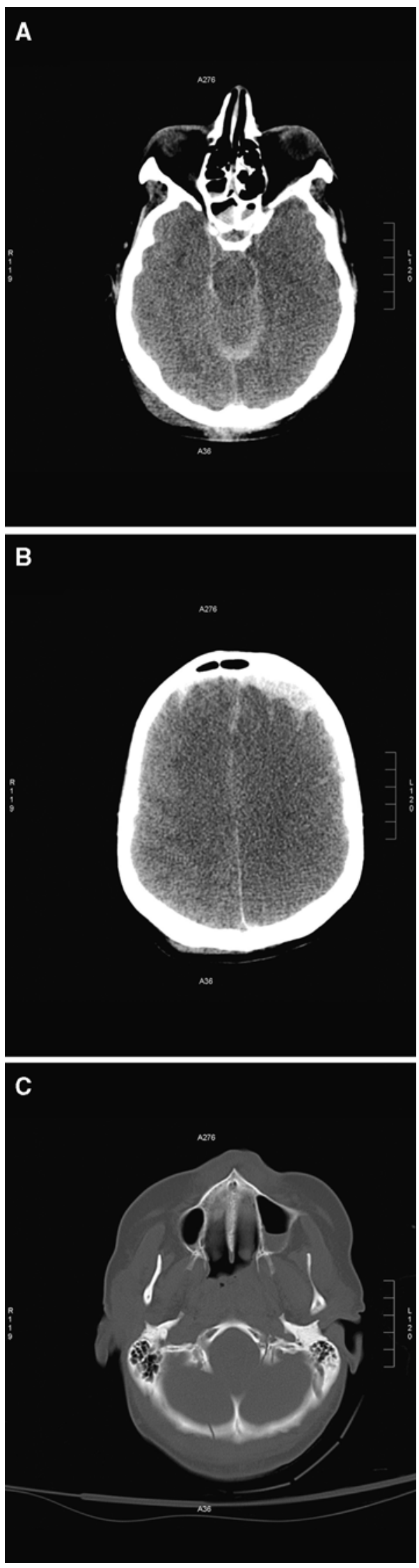


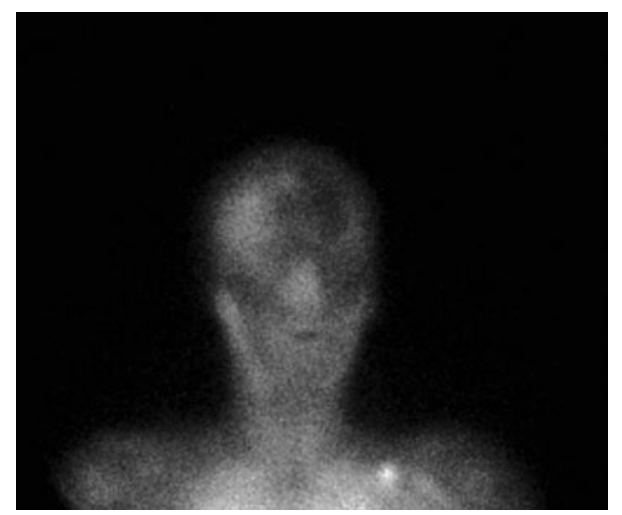

Fig. 5 Technetium 99 m-DTPA cerebral radionuclide angiogram performed following the return of spontaneous respiration for Case 2. There is uptake of the radionuclide on the right consistent with the presence of blood flow to the right cerebral hemisphere

a respiratory rate $>10$ breaths $\cdot \mathrm{min}^{-1}$ (ABG result 20-min subsequent: $\mathrm{pH}$ 7.41, $\mathrm{PaO}_{2} 216 \mathrm{mmHg}, \mathrm{PaCO}_{2} 34 \mathrm{mmHg}$ on a $\mathrm{F}_{1} \mathrm{O}_{2}$ of 0.5 ). The family was informed of the change, and a neurologist was consulted who found no evidence of brain or brainstem activity other than spontaneous respirations. After discussion with family, life support was withheld and the patient underwent cardiocirculatory collapse hours later.

\section{Discussion}

Herein, we present two patients who regained spontaneous respiration following NDD using clinical criteria (Table 1). For both cases, two physicians with considerable training and experience in NDD performed the primary declaration and a second neurosurgeon or neurologist subsequently confirmed their findings. Due to the presumed rarity of such cases, readers may question whether confounders were present that precluded the validity of the performed declarations or whether guideline recommendations were mis-applied.

For both cases, several unrecognized confounding factors were indeed present. First, although we know of no study that describes whether contrast enhancement is specific for brain blood flow, the presenting CT for Case 1 revealed mild perilesional ring enhancement, likely indicating slow cerebral arterial flow. In retrospect, this finding was associated with the return of spontaneous respiration and middle cerebral artery flow on MRI, and thus should have prompted use of a validated brain blood flow study. Despite our oversight on this, however, the clinical criteria for NDD (with the possible exception of the vestibuloocular reflex on the side affected by otitis media) appeared to have been met, which questions the sensitivity of the clinical examination for NDD.
By promoting recession of cerebral edema and/or by limiting further abscess expansion, the glucocorticoids and antibiotics given prior to NDD may have permitted the first patient's slow cerebral flow to continue. It is unknown whether this flow would have been sufficient to supply a subpopulation of more ischemia-resistant neurons within the medullary respiratory centre and induce spontaneous breathing. ${ }^{11}$ Aside from the fact that MRI has a low sensitivity for detecting low flow in patients with arterial stenosis (and is therefore not a recommended brain blood flow investigation), we have no explanation for ongoing respiration following receipt of the second MRI documenting absent brain blood flow. ${ }^{12}$

The return of spontaneous respiration with treatment in Case 1 could imply that a temporal lobe abscess was not an irreversible cause of acute brain injury. The Canadian Forum guideline states that an "established etiology capable of causing neurological death in the absence of reversible conditions capable of mimicking neurological death" must be present, and a prerequisite for NDD is "the absence of clinical neurological function with a known proximate cause that is irreversible." ${ }^{5}$ However, an intracranial mass with resultant brain herniation, which was the CT finding in our patient, is a common etiology and pathway of brain death. ${ }^{6}$ Xiao et al. reported that $62 \%$ of patients with a brain abscess and a GCS score $<9$ either died or fell into a vegetative state (unfortunately, these outcomes were not segregated), suggesting to us that a brain abscess was an etiology "capable" of causing neurological death. ${ }^{13}$ In support of this, two Royal College certified neurosurgeons at our tertiary centre felt that the patient's brain herniation syndrome was irreversible and capable of causing brain death.

Despite this, we know of few causes of absent neurological function that are universally "irreversible," aside from decapitation and permanent global ischemia with necrosis of whole brain. Most known proximate causes of brain death (e.g., traumatic intracranial hematoma) culminate in brainstem injury through brain herniation syndromes, but even these are occasionally reversible. Despite their overall dismal prognosis, some patients with a traumatic intracranial hematoma who present with a GCS score of 3 and fixed and dilated pupils can survive with treatment. ${ }^{14-16}$ Moreover, survival and even functional neurological recovery has been reported following predominantly medical reversal of transtentorial herniation secondary to a supratentorial mass lesion from a variety of causes. ${ }^{17-19}$ Survival with good outcome has even been reported after advanced cerebral herniation with Duret hemorrhage (a secondary brainstem hemorrhage that results from stretching and rupture of pontine perforating vessels during herniation), a condition commonly linked with brain death. ${ }^{16}$ 
Table 1 Canadian Forum recommendations fulfilled, investigations, and confounding factors for Cases 1 and $2^{5}$

\begin{tabular}{|c|c|c|}
\hline \multirow{2}{*}{$\begin{array}{l}\text { Recommendation, }{ }^{5} \text { investigation, or } \\
\text { confounding factor }\end{array}$} & \multicolumn{2}{|l|}{ Description or comment } \\
\hline & Case 1 & Case 2 \\
\hline $\begin{array}{l}\text { Established etiology capable of causing } \\
\text { neurological death }\end{array}$ & $\begin{array}{l}\text { Otogenic brain abscess with transtentorial } \\
\text { and tonsillar herniation* }\end{array}$ & $\begin{array}{l}\text { Intracranial hemorrhage with generalized } \\
\text { cerebral edema and effaced basal cisterns } \\
\text { along with a five-minute cardiac arrest }\end{array}$ \\
\hline $\begin{array}{l}\text { Deep unresponsive coma with pupils } \\
\text { mid-size or greater }\end{array}$ & GCS score of 3 with fixed 7-mm pupils & GCS score of 3 with fixed 6-mm pupils \\
\hline $\begin{array}{l}\text { Absent brainstem reflexes and motor } \\
\text { responses bilaterally }\end{array}$ & $\begin{array}{l}\text { Absent corneal, cough, gag, oculocephalic, } \uparrow \\
\text { pupillary, and vestibulo-ocular reflexes; } \\
\text { absent motor responses to pain }\end{array}$ & $\begin{array}{l}\text { Absent corneal, cough, gag, oculocephalic, } \dagger \\
\text { pupillary, and vestibulo-ocular reflexes; } \\
\text { absent motor responses to pain }\end{array}$ \\
\hline $\begin{array}{l}\text { Absent respiratory efforts based on the apnea } \\
\text { test }\end{array}$ & $\begin{array}{l}\text { Absent respiratory efforts over 10-min with } \\
\mathrm{PaCO}_{2} \text { rising from } 42 \mathrm{mmHg} \text { to } 69 \mathrm{mmHg} \\
\text { (rising }>20 \mathrm{mmHg} \text { ) with } \mathrm{pH} 7.18\end{array}$ & $\begin{array}{l}\text { Absent respiratory efforts over eight-min } \\
\text { with } \mathrm{PaCO}_{2} \text { rising from } 56 \mathrm{mmHg} \text { to } \\
80 \mathrm{mmHg} \text { (rising }>20 \mathrm{mmHg} \text { ) with } \mathrm{pH} \\
7.15\end{array}$ \\
\hline Absent confounding factors & $\begin{array}{l}\text { Absent shock, hypothermia (temperature } \\
36.5^{\circ} \mathrm{C} \text { ), metabolic or biochemical } \\
\text { abnormality, neuromuscular dysfunction } \\
\text { (train-of-four test negative), or drug } \\
\text { intoxication; no sedative agents given }\end{array}$ & $\begin{array}{l}\text { Absent shock, hypothermia (temperature } \\
36.5^{\circ} \mathrm{C} \text { ), metabolic or biochemical } \\
\text { abnormality, or drug intoxication; no } \\
\text { sedative or neuromuscular blocking agents } \\
\text { given }\end{array}$ \\
\hline Present confounding factors & $\begin{array}{l}\text { Otitis media with mastoiditis } \ddagger \\
\text { Mild perilesional ring enhancement on CT§ }\end{array}$ & A five-minute cardiac arrest \\
\hline Two physicians declaring brain deathll & An intensivist and a neurosurgeon & Two intensivists \\
\hline $\begin{array}{l}\text { Ancillary brain blood flow analysis when it is } \\
\text { not possible to confirm brain death by } \\
\text { clinical criteria }\end{array}$ & $\begin{array}{l}\text { Not recommended; } \S \mathrm{CT} \text { suggesting and MRI } \\
\text { revealing the presence of bilateral cerebral } \\
\text { blood flow }\end{array}$ & $\begin{array}{l}\text { Recommended; cerebral radionuclide } \\
\text { angiogram showing blood flow to the right } \\
\text { cerebral hemisphere }\end{array}$ \\
\hline Autopsy neuropathology findings & $\begin{array}{l}\text { Not necessary, but requested; necrosis of } \\
\text { temporal lobe and select other hemispheric } \\
\text { regions along with ischemic changes in the } \\
\text { pons and medulla }\end{array}$ & Not necessary and not requested \\
\hline
\end{tabular}

*In one study, approximately $62 \%$ of patients with a brain abscess and a GCS score $<9$ either died or fell into a vegetative state, which suggests to us that a brain abscess was "capable" of causing neurological death. ${ }^{13}$

$\dagger$ Although assessment of this reflex is not recommended by Canadian Forum guidelines and some have questioned its sensitivity, its absence supports the lack of clinically detectable brainstem function. ${ }^{5}$

$¥$ Although we found no otoscopic or pathological evidence of acute middle ear disease or middle ear effusion, in theory this condition could impact assessment of the vestibulo-ocular reflex. A search of the existing medical literature, however, revealed no specific study or mention of otitis media with mastoiditis as a confounding factor.

§The presence of mild perilesional ring enhancement likely indicated slow cerebral arterial flow and thus should have prompted use of a validated brain blood flow analysis.

IIThere are approximately 15 to 20 such declarations per year at our centre, and the physicians involved had considerable training and experience in NDD.

$\mathrm{CT}=$ computed tomography; GCS = Glasgow Coma Scale; MRI = magnetic resonance imaging or image; NDD = neurological determination of death; $\mathrm{PaCO}_{2}=$ partial pressure of carbon dioxide.

A second finding that possibly influenced the NDD in the first case was the presence of chronic otitis media with mastoiditis. Although we found no otoscopic or pathological evidence of acute middle ear disease or middle ear effusion in our patient, in theory this condition could have impacted assessment of the vestibulo-ocular reflex. However, a search of the existing medical literature revealed no specific study or mention of otitis media with mastoiditis as a confounding factor. Such possible, but unstudied and thus unsubstantiated, confounding factors are where superior clinical judgement (a concept supported by the Canadian
Forum guideline) is imperative. ${ }^{5}$ However, we argue that clinical judgement is a vague and imprecise recommendation for a NDD guideline. The common occurrence of confounding factors, both proven and unproven, combined with a requirement for high diagnostic specificity, suggest to us that use of clinical criteria and judgement alone is problematic.

Finally, the NDD in the second case could have been influenced by a cardiac arrest within six-hr. In cases of acute hypoxic-ischemic brain injury, the Canadian Forum recommends that "clinical evaluation for NDD should be 
delayed for 24-hr subsequent to the cardiorespiratory arrest or an ancillary test could be performed". 5 However, it is difficult to apply this recommendation to our patient and possibly to all patients with traumatic brain injury due to limitations of the study on which this recommendation appears to be based. The study, a systematic review and meta-analysis, reported that assessments of motor responses and ocular reflexes in post-cardiac arrest coma were unreliable for determining brain death or poor prognosis in the subsequent 24-hr. ${ }^{20}$ However, few of the patients in this meta-analysis also had traumatic brain injuries. ${ }^{20}$ The prognosis of those with a brain injury who subsequently arrest is likely far worse than that reported in this study as hypotension in these patients is a powerful predictor of poor outcome. ${ }^{21}$ An episode of hypotension in a patient with a traumatic brain injury is associated with a two- to five-fold higher rate of mortality compared with those without hypotension. ${ }^{21,22}$

Although our clinical experience suggests that these are unusual cases, we wonder if they might become more prevalent with changing organ donor management. Aggressive hormonal resuscitation and increased efforts to utilize organs of older, high-risk, and bacteremic (as in the first case) donors may narrow the gap between needed and available organs. ${ }^{23,24}$ However, these therapies could also prolong the time interval from NDD to organ retrieval and thus create previously unforeseen situations, such as we described herein. Kohrman and Spivak ${ }^{25}$ presented a case of a three-month-old girl who also fulfilled criteria for brain death and subsequently regained spontaneous respiration. These authors urged for prolonged observation before NDD in infants, and we wonder whether a similar recommendation is warranted for adults. However, we appreciate that a prolonged declaration process could lead to increased financial costs and loss of potential organs. We believe that brain blood flow analyses, in combination with clinical examination and apnea testing, should play a larger role than they do currently. This approach could alleviate concerns about increasing observation times while simultaneously providing reassurance to all that brain death has occurred.

Herein, we present two cases of patients who had a return of spontaneous respiration following clinical NDD, as several confounding factors were overlooked, including perilesional ring enhancement on $\mathrm{CT}$, chronic otitis media with mastoiditis, and a cardiac arrest within six-hr. However, with the possible exception of a recent cardiac arrest, these confounding factors are both unstudied and unsubstantiated, which is likely the case for many of the confounding factors for the clinical examination for NDD. Therefore, these cases highlight the difficulties encountered by experienced clinicians in determining brain death by clinical criteria alone. It is our suspicion that other such cases exist and likely reflect the present knowledge deficiencies regarding confounding factors and the inherent errors in relying primarily on clinical examination and judgement for most cases of NDD. We hope that our findings encourage colleagues to come forward with their experiences if similar to ours and that they stimulate discussion and promote ongoing critical examination of existing guideline recommendations. As the state of brain death can only be guaranteed by the persistent absence of brain blood flow, it leads us to recommend the requirement for validated ancillary radiological studies in the routine declaration of neurological death.

Acknowledgements We thank Dr. Kerry B. Goralski at Dalhousie University in Halifax, Nova Scotia, Canada for his assistance with formatting our figures and the families of the deceased for allowing us to present their clinical information.

Disclosure This report was reviewed and approved by the Capital District Health Authority Research Ethics Board. The authors report no conflict of interest concerning the findings specified in the paper. Dr. Richard I. Hall had full access to all details of the case reports and had the final responsibility for the decision to submit for publication.

There are no funding sources that supported the submitted work or any commercial or non-commercial affiliations that may be perceived to be a conflict of interest with the work presented herein.

\section{References}

1. Wijdicks EF. Brain death worldwide: accepted fact but no global consensus in diagnostic criteria. Neurology 2002; 58: 20-5.

2. Hornby $K$, Shemie SD, Teitelbaum J, Doig C. Variability in hospital-based brain death guidelines in Canada. Can J Anesth 2006; 53: 613-9.

3. Greer DM, Varelas PN, Haque S, Wijdicks EF. Variability of brain death determination guidelines in leading US neurologic institutions. Neurology 2008; 70: 284-9.

4. Powner DJ, Hernandez M, Rives TE. Variability among hospital policies for determining brain death in adults. Crit Care Med 2004; 32: 1284-8.

5. Shemie $S D$, Doig $C$, Dickens B, et al. Severe brain injury to neurological determination of death: Canadian forum recommendations. CMAJ 2006; 174: S1-13.

6. Wijdicks EF. The diagnosis of brain death. N Engl J Med 2001; 344: 1215-21.

7. Lang CJ, Heckmann JG. Apnea testing for the diagnosis of brain death. Acta Neurol Scand 2005; 112: 358-69.

8. Shemie SD, Lee D, Sharpe M, Tampieri D, Young B, Canadian Critical Care Society. Brain blood flow in the neurological determination of death: Canadian expert report. Can J Neurol Sci 2008; 35: 140-55.

9. Wijdicks EF, Rabinstein AA, Manno EM, Atkinson JD. Pronouncing brain death: Contemporary practice and safety of the apnea test. Neurology 2008; 71: 1240-4.

10. Kutsogiannis DJ, Pagliarello G, Doig C, Ross H, Shemie SD. Medical management to optimize organ donor potential: review of the literature. Can J Anesth 2006; 53: 820-30.

11. Shemie $S D$. Clarifying the paradigm for the ethics of donation and transplantation: was "dead" really so clear before organ donation? Philos Ethics Humanit Med 2007; 2: 18. 
12. Heran MK, Heran NS, Shemie SD. A review of ancillary tests in evaluating brain death. Can J Neurol Sci 2008; 35: 409-19.

13. Xiao F, Tseng MY, Teng LJ, Tseng HM, Tsai JC. Brain abscess: clinical experience and analysis of prognostic factors. Surg Neurol 2005; 63: 442-50.

14. Mauritz W, Leitgeb J, Wilbacher I, et al. Outcome of brain trauma patients who have a Glasgow Coma Scale score of 3 and bilateral fixed and dilated pupils in the field. Eur J Emerg Med 2009; 16: 153-8.

15. Chamoun RB, Robertson CS, Gopinath SP. Outcome in patients with blunt head trauma and a Glasgow Coma Scale score of 3 at presentation. J Neurosurg 2009; 111: 683-7.

16. Stiver SI, Gean AD, Manley GT. Survival with good outcome after cerebral herniation and Duret hemorrhage caused by traumatic brain injury. J Neurosurg 2009; 110: 1242-6.

17. Qureshi AI, Geocadin RG, Suarez JI, Ulatowski JA. Long-term outcome after medical reversal of transtentorial herniation in patients with supratentorial mass lesions. Crit Care Med 2000; 28: 1556-64.

18. Skoglund TS, Nellgard B. Long-time outcome after transient transtentorial herniation in patients with traumatic brain injury. Acta Anaesthesiol Scand 2005; 49: 337-40.

19. Koenig MA, Bryan M, Lewin JL III, Mirski MA, Geocadin RG, Stevens $R D$. Reversal of transtentorial herniation with hypertonic saline. Neurology 2008; 70: 1023-9.
20. Booth CM, Boone RH, Tomlinson G, Detsky AS. Is this patient dead, vegetative, or severely neurologically impaired? Assessing outcome for comatose survivors of cardiac arrest. JAMA 2004; 291: 870-9.

21. Anonymous. The Brain Trauma Foundation. The American Association of Neurological Surgeons. The Joint Section on Neurotrauma and Critical Care. Resuscitation of blood pressure and oxygenation. J Neurotrauma 2000; 17: 471-8.

22. Schreiber MA, Aoki N, Scott BG, Beck JR. Determinants of mortality in patients with severe blunt head injury. Arch Surg 2002; 137: 285-90.

23. Rosendale JD, Kauffman HM, McBride MA, et al. Aggressive pharmacologic donor management results in more transplanted organs. Transplantation 2003; 75: 482-7.

24. Salim A, Velmahos GC, Brown C, Belzberg H, Demetriades D. Aggressive organ donor management significantly increases the number of organs available for transplantation. J Trauma 2005; 58: 991-4.

25. Kohrman $M H$, Spivak BS. Brain death in infants: sensitivity and specificity of current criteria. Pediatr Neurol 1990; 6: 47-50. 